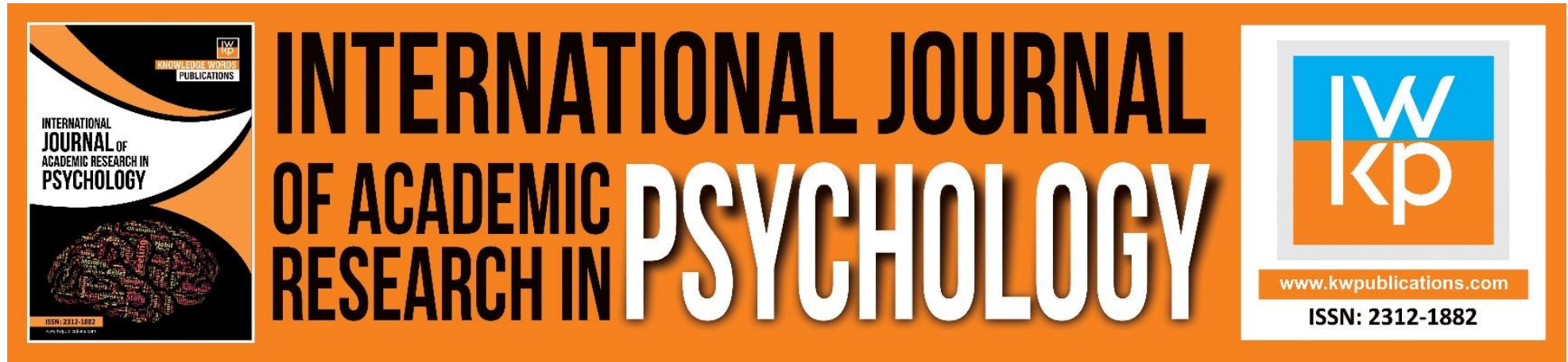

\title{
Effectiveness of Training Sensory Stimulation on Gross Motor Skills of 5-7 Years Old Children with Down Syndrome
}

Kamal Parhoon, Hadi Parhoon, Guita Movallali

To Link this Article: http://dx.doi.org/10.46886/IJARP/v4-i1/722 DOI:10.46886/IJARP/v4-i1/722

Received: 09 September 2017, Revised: 05 November 2017, Accepted: 09 December 2017

Published Online: 26 December 2017

In-Text Citation: (Parhoon et al., 2017)

To Cite this Article: Parhoon, K., Parhoon, H., \& Movallali, G. (2017). Effectiveness of Training Sensory Stimulation on Gross Motor Skills of 5-7 Years Old Children with Down Syndrome. International Journal of Academic Research in Psychology, 4(1), 43-52.

\section{Copyright: (c) 2017 The Author(s)}

Published by Knowledge Words Publications (www.kwpublications.com)

This article is published under the Creative Commons Attribution (CC BY 4.0) license. Anyone may reproduce, distribute, translate and create derivative works of this article (for both commercial and non-commercial purposes), subject to full attribution to the original publication and authors. The full terms of this license may be seen at: http://creativecommons.org/licences/by/4.0/legalcode

\section{Vol. 4, No. 1, 2014, Pg. 43 - 52}

Full Terms \& Conditions of access and use can be found at https://kwpublications.com/pages/detail/publication-ethics 


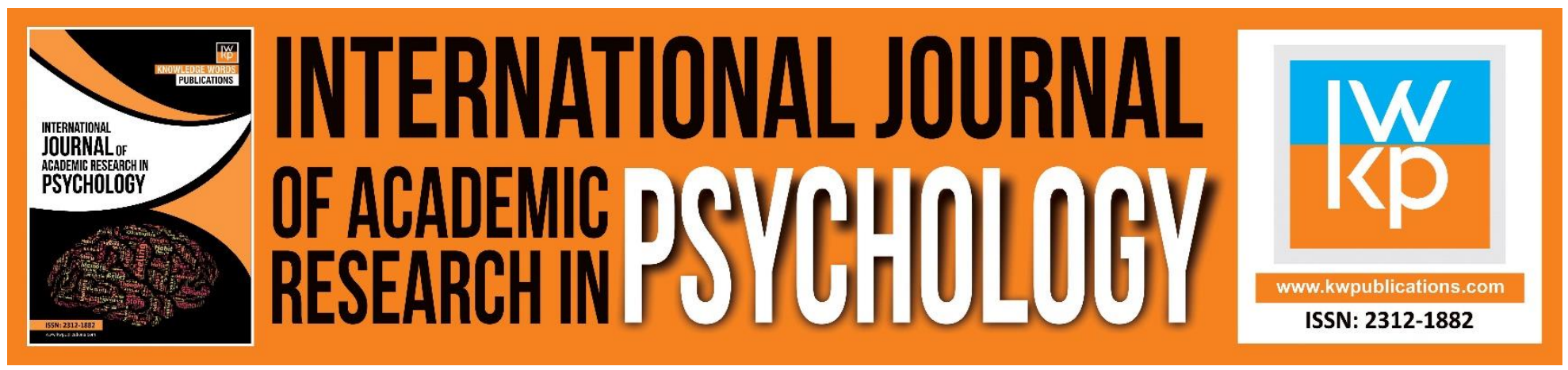

\title{
Effectiveness of Training Sensory Stimulation on Gross Motor Skills of 5-7 Years Old Children with Down Syndrome
}

\author{
Kamal Parhoon, Hadi Parhoon, Guita Movallali \\ ${ }^{1}$ MA Psychology and Exceptional Children Education, University of Social Welfare and Rehabilitation \\ Sciences, Tehran, Iran, 2PhD Student. Health Psychology, Faculty of Psychology and Educational \\ Sciences University of Kharazmi, ${ }^{3}$ Assistant Professor in Psychology and Education of Exceptional \\ Children, Pediatric Neurorehabilitation Research Center, University of Social Welfare \& \\ Rehabilitation Sciences (USWR), Tehran, Iran. \\ Email: kamalparhon110@gmail.com
}

\begin{abstract}
Background: Down syndrome is the most common congenital chromosomal disorders. This disorder is the most common genetically cause of mental retardation. This study examined the effectiveness of the training activities of sensory - motor (sensory stimulation) on gross motor skills in children 5 to 7 year-old with Down syndrome. In this study, participant consisted from children aged 5 to 7 years old who were members of Iranian Down syndrome society. The aim of investigation was the effectiveness of sensory - motor influence (sensory stimulation) on gross motor skills in children 5 to 7 year old with Down syndrome.

Materials and Methods: The present study had an experimental design and a pre test, post test plan with control group were used. For this purpose 24 children (aged 5-7 years old) were choose randomly from the Down Syndrome Association. Subjects were divided in two groups (experimental and control each 12 children) randomly. Treatment sessions were 16 with duration of 35 minutes Under the influence of sensory stimulation therapy (activities of sensory - motor).The control group didn't receive any intervention The research instrument was used in this study was Lincoln Oseretsky motor development Scale. The collected data were analyzed by covariance.

Results: Results showed that there was a significant relationship between the training of sensory stimulation and gross motor skill development in children with Down syndrome. $(P<0.001)$

Conclusion: Sensory stimulation and early education of children with Down syndrome by motor abilities will make them self-efficacy and independent.
\end{abstract}

Keywords: Sensory Stimulation, Gross Motor Skills, Down Syndrome. 
INTERNATIONAL JOURNAL OF ACADEMIC RESEARCH IN PSYCHOLOGY

Vol. 4, No. 1, 2017, E-ISSN: 2312-1882 @ 2017 KWP

\section{Introduction}

Down's syndrome is the most common congenital chromosomal disorder that is always with mental retardation $(1,2)$. The statistical analyses in different countries show that the incidence of this disorder is 1 in 700 to 1 in 900 per live birth $(3,4)$. This incidence percentage increases with the increment of pregnant age. With considering the total number of people with mental retardation within 5 to 6 percent, Down's syndrome is the most prevailing form of mental retardation $(3,4)$ the rate of mental retardation for people with Down's syndrome is so different, but the evidence suggests that most of these people are being classified into the mild mental retardation category $(5,1)$. On the one hand, children with Down's syndrome gross motor skills shape with delay and ineffectiveness as the mentioned children have got the following problems: Weak muscular tone, muscular flaccidity, weak bilateralism coordination, dyspraxia, the delay in physical developmental route, the shortness of bones in limbs, the tardiness in reflexes growth and their completion, the lateness in the growth of positional reactions, the specific anatomical - physiological traits of hand ( the shortness of hand length, having 23 bones instead of 27, low range of motion of joints, the shortness of fingers, abnormal lines and arches in palms, and the delay in grasping activities), the decrease in awareness of inputs and the enervation in tactile discrimination, steregnosis and the manipulation of objects(1, $5,6)$.

On the other hand, these children display sensible deficiencies that result in the restriction in sensory experience and difficulty in normal motor control (7).

Sensory stimulations include different resources and qualities of energy that cause the act potential in related receptors to various senses such as auditory, visual, tactile, and vestibular; and finally individuals become aware of the stimulation of receptor organ through brain and show suitable reaction to that $(5,8,9)$. Or rather the sensory integration treatment 'in general' and sensory stimulations in particular' include controllable sensory motivations that mostly involve selfgoverning activities that generates adaptive response and the integration of proprioceptive, tactile, and vestibular inputs that engenders the improvement in motor and behavioral responses $(10,11)$.

It's worth mentioning children with Down's syndrome have so many problems in development of motor skills, and considering the importance of motor skills in keeping the child's independence and the expansion of the other skills such as self-helping, play educational skills, and in general person's adaptation with environment, the development of gross motor skills is considered an important and remarkable issue in the improvement of these children's function and growth (11).

Regarding the high incidence of Down's syndrome and the awareness of the capability of suitable response to the rehabilitation plans ( Due to having apt developmental potentials) giving attention to these children and fine planning are indispensable needs for promoting the condition of their social, mental, and physical health.

As in so many researches the existence of processing problems and sensory integration in these children has appeared and its influence has been proved on the field of motor development.

Hernandez and et al, Zimmer and et al, Deli and et al, and Wang, J in various investigations have verified effectiveness of the following treatment plans: The effect of gross motor skills on the boy pupils' attention process with Down's syndrome, the influence of the sensory integration treatment on fine and gross motor skills in 5-7 year old children with Down's syndrome, efficacy of proprioceptive and simultaneous motivations over 6-7 year old children's dexterity with this syndrome, the influence of sensory integration method and training motor-perception skills on 
motor problems of dyslexic children, the investigation of the influence of sensory stimulations and motor exercises on hand skills in mentally-retarded children, learning of gross motor activities in adolescents with Down's, the effectiveness of sensory integration treatment, the combination of sensory integration method with vestibular motivations(3, 5, 7, 9, 12-19).

On the one hand Since the existence of processing problems and sensory integration in children with Down's syndrome and its influence on the motor development is an obvious matter; and on the other hand as therapists have access to effective treatment approaches for obviating these setbacks; the enough research in relation to the influence of this treatment method has not been done

On children's motor development with Down's

While the scrutiny of the usefulness of sensory stimulation remedy in different disorders needs numerous surveys.

With giving attention to the importance of motor skills in the preservation of the child's independence, the development of motor skills in children with Down's syndrome should be taken into account; therefore this study was done with the aim of surveying the influence of sensory stimulation treatment training on 5-7 year old children's gross motor activities with Down's syndrome.

Here it should be told that the resulted outcomes of this research in the effectiveness direction of sensory motivations could open a new window on the horizon of rehabilitation and motor independence in children with Down's syndrome for specialists, therapists, and even children's parents.

\section{Materials and Methods}

The present research was done in the frame of a quasi-experimental design with pre-test, post-test along with the control group. Two subject and control groups participated in this research, and pretest and post-test were implemented on each of two groups.

The statistical society of the research included all of the 5-7 year old children with Down's syndrome who had referred to the rehabilitation center of Rezvaan and the association of Down's syndrome in 89-90 of the Iranian calendar.

Out of 43 children with Down's syndrome whose parents had consent to their participation in the research; and in terms of entrance and exit conditions, only 24 of them ( males) with Down's syndrome were chosen and divided into 12-individual two groups ( Subject and Control) through the random method.

After choosing the samples and specifying the mentioned groups, Lincoln-Ozeretsky Development Test was performed over them.

The observed entrance and exit conditions in selecting children were as follows:

The entrance criteria:

The contraction to Down's syndrome, having 5-7 years old, being male, not using of the sensory stimulation treatment during the survey period or before that (except the therapist's intervention in intermediation group), being volunteer and having the parents' consent for the children's participation in the research.

The exit criteria:

The existence of the severe and profound mental delay, severe convulsion, tough orthopedic disorders, the child's contraction to a debilitating disease during the intervention period provided 
INTERNATIONAL JOURNAL OF ACADEMIC RESEARCH IN PSYCHOLOGY

Vol. 4, No. 1, 2017, E-ISSN: 2312-1882 @ 2017 KWP

that the urgent hospitalization or surgery operation will be needed, the nonparticipation in the intervention sessions for 3 consecutive times or more.

\section{Tool}

\section{Lincoln-Ozeretsky's Motor Development Scale}

This tool is a set of standard tests including 36 sub-tests with the scoring from 0 to 3 and has been designed for assessing children's motor ability within 5-14 years old.

This scale is being performed individually and evaluates and meters different motor skills like fingers ability, the coordination of eye-hand, and the activity of large muscles of hands, arms, feet, and trunk. This scale is a motor index that consists of fine and gross movements and has 6 sub-scales.

These six sub-scales conti the general static co-ordination, the total dynamic co-ordination. The dynamic hand co -ordination, motor agility, voluntary simultaneous movements, and motor inconsistency.

The splitting method has been used for the investigation of the reliability of the test, and the reliability coefficient has been calculated $97 \%$ by Spearman- Brown formula. The reliability coefficient with the splitting method has yielded $94 \%$ for this research.

\section{Therapeutic Interventions}

After the necessary co- ordinations, Lincoln-Ozeretsky motor development test was performed during three sessions among children. The identified children after the performance of LincolnOzeretsky Test were divided into two groups (Subject and Control) that children had been assimilated in terms of the age and the scores of motor development test. The control group did not receive any intervention and only kept the track of the usual trainings. But the subject group enjoy the needed instructions for 4 gross motor activities and its sub-skills during 16 sessions ( With pre-test and posttest) for 2 months, weekly 2 sessions in 35 minutes, After finishing the educational sessions LincolnOzeretsky motor development test was applied for both of two groups, and in the last stage the garnered data of subjects was analyzed through SPSS Software and multifactor covariance analyses test( MANCOVA).

\section{Training in Static Vestibular Position: (4-6 sessions)}

The vestibular exercises consist of relatively static position while arms, knees, and head are put in contact with the mat. In general, these activities have become ancillary with the help of different kinds of imaginations and embodiments. For example, it is suggested to the child to make a bridge over the river through his body. In the next stage, the child is asked to create the mentioned bridge with three parts of his body while one of them is the wrist, or he uses two parts of his body whereas one of them is his knee.

\section{Training in Dynamic Vestibular Position: (6-8 sessions)}

Here the vestibular balance board is placed up the surface of ground for walking and gets narrower ,or another option is that the various objects with different heights are laid over the balance board to test the child's ability in passing over them, or some barriers are located up the wood and the child is forced to cross under them. 
INTERNATIONAL JOURNAL OF ACADEMIC RESEARCH IN PSYCHOLOGY

Vol. 4, No. 1, 2017, E-ISSN: 2312-1882 @ 2017 KWP

\section{Training Rapid and Agile Movements: (8-10 sessions)}

The given rapid movements to children include the movements in which the involvement of hands and feet are seen, and those in which the body movements are in the directions of up, down, forth, and back.

\section{Training Rapid Movement and Along with Motion: (10-13 sessions)}

They consist of the kinetic skills in the child's motor plan. Gamboling, jumping, and running were the problematic changes. As it is needful in many games to see the child who moves in different angles and has some pauses, some activities the same as the above ones were given to the child that were related to standing and moving with each other. The child was persuaded to move backward and then to stop, and or move to backward in left and right directions and after that stop.

The actions of standing or stopping were trained to the child through the explanation and showing the special pattern. Thus the child was bringing his gravity center to some extent down by bending the knees to have a pause in that situation.

\section{Training Hand Skills in controlling the Ball: (13-16 sessions)}

Throwing: comprising of hand movements alone- shifting the weight of one foot on his own, weight shifting of foot and arm at the same time without the ball, weight transferring of foot and arm simultaneously with one ball, the practice for increasing the child's attention in hitting the ball to horizontal and vertical targets.

Grasping the ball: Hitting gently the ball, looking, touching and trying in grasping the ball that is hung from the rope and moving from right to left, far to near. Attempting in taking a ball that is hung and rotatory in front of the child through the rope. As saying in grasping the ball that is hung in different axes while the child is in a lying position.

\section{Results}

27 children with Down's syndrome participated in this research. The youngest child was 5 years old and the oldest one 7 years old. The Statistical indexes of the subjects' age concerning the group have been reported in Table 1.

\section{Table 1: Descriptive Indexes of the Subjects' age Concerning the Group}

$\begin{array}{llllllll}\text { Groups } & \mathbf{N} & \text { Max } & \text { Min } & \text { M } & \text { SD } & \mathbf{t} & \mathbf{P} \\ \text { Experimental } & 12 & 7 & 5 & 9.34 & 2.12 & .180 & .756 \\ \text { Control } & 12 & 7 & 5 & 9.12 & 2.30 & & \end{array}$

Regarding the written figures in Table 1, the average of the subjects' age of the experimental group was more compared to the control group. The isotropy of the control and experimental groups in the age average was analyzed through the statistical test called Independent T. There was not the significant statistical difference in the subjects' age average in control and experimental groups ( $p=$. / 756)

The subjects' scores were examined in the skills of the body's equilibrium, the co-ordination of hand and foot, grasping and throwing, and the gross motor skills. (Table 2) 
INTERNATIONAL JOURNAL OF ACADEMIC RESEARCH IN PSYCHOLOGY

Vol. 4, No. 1, 2017, E-ISSN: 2312-1882 @ 2017 KWP

Table 2: Descriptive indices of gross motor for experimental and control groups in pretest and posttest situations
Experimental group
Control group

\begin{tabular}{lllllllll} 
Variable & Pretest & \multicolumn{3}{c}{ Posttest } & \multicolumn{3}{c}{ Pretest } & \multicolumn{3}{c}{ Posttest } \\
& & & & & & & & \\
& M & SD & M & SD & M & SD & M & SD \\
$\begin{array}{l}\text { Motor } \\
\text { coordination }\end{array}$ & 2.92 & 1.93 & 4.50 & 1 & 2.83 & 1.34 & 2.25 &.$/ 96$ \\
$\begin{array}{l}\text { Balance } \\
\text { Catch and }\end{array}$ & 5.25 & 1.21 & 3.92 & 1.78 & 2.75 & 1.36 & 3.42 & $\mathbf{2 . 1 1}$ \\
throw & 5 & 2.33 & 6.58 & 2.27 & 4.50 & 2.75 & 3.58 & $\mathbf{1 . 9 7}$ \\
Jumping & 7.83 & 2.04 & 14.50 & 4.14 & 4.92 & 2.99 & 13.25 & $\mathbf{3 . 3 9}$ \\
Gross motor & 2.67 & 1.37 & 24.17 & 3.88 & 2.50 & 1 & 13.50 & $\mathbf{4 . 2 3 .}$
\end{tabular}

As Table 2 shows there are some differences between the average of control group and experimental one in the research variables; but being significant of these differences is not clear to us. Then for comparing the group the multi variate covariance analyses has been used regarding the existence of some dependent variables and their interval nature and also the performance of pre test.

The results of Hotling multi variate test are significant in statistical context, that is to say, at least in one variable the difference is significant between control and experimental groups. Then for showing more details the intergroup differences have been reported in Table 3.

Table 3: Results of MANCOVA for comparing the components of gross motor in two groups

$\begin{array}{lllllll}\begin{array}{l}\text { Source of } \\ \text { change }\end{array} & \text { SS } & \text { D f } & \text { MS } & \text { F } & \text { Sig } & \mathbf{2 n} \\ \begin{array}{l}\text { Motor } \\ \text { coordination }\end{array} & 24.34 & 1 & 24.34 & 65 / 53 & 0 / 001 & . / 78 \\ \begin{array}{l}\text { Balance } \\ \text { Catch and }\end{array} & 20.34 & 1 & 20.34 & 22 / 26 & 0 / 001 & . / 55 \\ \text { throw } & 64.27 & 1 & 64.27 & 25 / 83 & 0 / 001 & . / 59 \\ \text { Jumping } & 87.38 & 1 & 87.38 & 19 / 34 & 0 / 001 & . / 52 \\ \text { Gross motor } & 86.537 & 1 & 86.537 & 113 / 86 & 0 / 001 & . / 86\end{array}$

As Table 3 demonstrates in all of the variables including co-ordination( $p$ less than $0 / 01, F=65 / 53$ ), vestibular ( $p$ less than $0 / 01, F=22 / 26$ ) grasping and throwing ( $p$ less than $0 / 01, F=25 / 83$ ) jumping ( $p$ less than 0/01, $F=19 / 34$ ) and gross motor ( $P$ less than, $F=113 / 86$ ), the difference between two groups was significant that the consideration of the averages' table shows that in all variables the average of the experimental group was higher than the control group. It means, training sensory motivations has resulted in the improvement of motor skills. 
INTERNATIONAL JOURNAL OF ACADEMIC RESEARCH IN PSYCHOLOGY

Vol. 4, No. 1, 2017, E-ISSN: 2312-1882 @ 2017 KWP

\section{Discussion}

The results of the multi -variate covariance analyses smack of that after the intervention, the scores average of the experimental group have increased than the control group, and this difference is significant in statistical situation.

Then acquired results could be interpreted in this way that regarding this issue that the children with Down's syndrome have the obvious retardations in the development of fine and gross motor skills and these delays leave the devastating effects on these children's development and function in daily activities of life(7). As the integration and sensory processing are important and influential factors in the children's independence with Down's syndrome, in this research with emphasis on training sensory motivations through the improvement of the central system function in processing and the integration of data, tangible breakthroughs have come up in the amendment process of motor skills in these children. Then it would be said that training sensory motivations increases gross motor skills in children with Down's syndrome. So many researches in the field of sensory motivations effects on motor skills in children with Down's syndrome and mental retardation have been performed, the results of this research is in harmony with the outcomes of some researches and in loggerheads with the outcomes of the others. Acquired results of this investigation with the Soortchi's, Mollajani's, Yanic and et al has got the similarity who had used sensory integration treatment for the development of fine and gross motions in mentally-retarded children with Down's syndrome. Also the outcomes of this study with the results of Asadidoost, Hamphries and et al who had used sensory integration treatment for children without mental retardation and with the results of Zimmer et al, Daily et al, Wang, Feddri et al, Fakhri, Aaghaee and Khajeh Hoseini has got the same equality who have emphasized the intervention effectiveness on the improvement of motor skills in children. Among the researches whose results were inconsistent with this study results we can name Miller's investigation that neither rejects nor accepts the effectiveness of sensory integration treatment. For the explanation of this matter that why the training sensory stimulation causes the improvement of gross motor skills in children with Down's syndrome, we should tell that although the development of motor skills start before the birth and continue in all of life, the improvement in motor skills need the maturation of bio-cognition and psycho-cognition systems, and learning also has got an undeniable role in this improvement. In following of the development of children's motor skills we understand that the changes of motor behaviors goes forward in terms of a hierarchical system and from simple movements to complicated ones. Any impairment in these stages causes stop and impairment in complicated stages that gross motor skills such as running, hopping, and jumping are of these skills $(3,7,12,15,17-20)$.

The appearance of normal developmental changes to a great deal depends on the integration and interpretation of the stimulations and sensory inputs and child's first sensory experience. The more the child is good at processing of received sensory data of the environment and his body, the more the child will be successful in passing the next movement stages and improvement towards the complicated motor skills, abstract activities, and also the automation of the mentioned skills(10, 21, 22). Regarding the acquired findings in this research, we saw that after the intervention the average of the subject's group scores increased and outcomes were explanatory of the meaningful difference of this variation. Then we can claim that the training sensory motivations engenders the improvement of body equilibrium, hand and foot co-ordination, grasping and throwing, and also jumping skills, and in general gross motor skills in children with Down's syndrome. 
INTERNATIONAL JOURNAL OF ACADEMIC RESEARCH IN PSYCHOLOGY

Vol. 4, No. 1, 2017, E-ISSN: 2312-1882 @ 2017 KWP

\section{Conclusion}

The results of the study showed that training sensory motivations has got the positive effects on the skills of body equilibrium, co-ordination of hand and foot, jumping and in general children's gross motor skills with Down's syndrome. Then the consideration of this issue could have the deep effect on the rehabilitation of children with Down's syndrome.

\section{Acknowledgement}

This article is a part of research project supported by Deputy of Research and Technology of University of Social Welfare and Rehabilitation Sciences. We would like to thank Deputy of Research and Technology of the University. We also wish to thank all of the boy Down syndrome children in Tehran Province for their valuable collaboration with this study.

\section{Authors' Contributions}

All authors had equal role in design, work, statistical analysis and manuscript writing.

\section{Conflict of Interest}

The authors declare no conflict of interest.

\section{Funding/Support}

Social Welfare and Rehabilitation Sciences University.

\section{Reference}

Asadidost, N. (2008). Effects of sensory integration and perceptual skills - motor movement problems dyslexic children based on the first three elementary schools in Isfahan. Isfahan, Iran: Psychology and education of exceptional children.

Bahram, A., Shafizadeh, M. (2007) Learning skill motor Application of the principles. edition F, editor. Tehran: Nrsy. 36-75.

Barnett, L., Beurden, V. E., Morgan, P., Brooks, L., Beard, J. (2009) Childhood motor skill proficiency as a predictor of adolescent physical activity. JJournal of Adolescent Health. 44(3),252- 9.

Daniel, P. H., James, M. K. (2005) Exceptional children introduction to special education. edition $n$, editor2005. 177-94.

Emmons, P. L. A. (2007) Understanding sensory Dysfunction (2th ed); 2007 P-. Understanding sensory Dysfunction2007.

Eric, J. M., David, A. W. (2008) Makiabadi M AAFeTRP. Abnormal Child Psychology. 234-46.

Fakhri, F., Aghaei, H., Khajehosseini, H. (2005) effectiveness of drama therapy on increasing of motor skills and hearing skills of Male intellectual disabled with an I.Q between 55-70 in the Age Range of 10-15 years. Qurterly jornal of rehabilitation university of social welfare \& rehabilitation sciences. 6(2), 7-12.

Fowler, S. (2007). Sensory Stimulation. Lessica Kingsley publishers London and Phladelphia, 125- 45.

Hernandez, T., Field, T., Largie, S., Mora, G., Bornstein, R. (2006) WaldmanChildren With Down Syndrome improved in motor functioning and muscle tone following massage therapy. Early child developmental and care. 176(3), 395-410. 
Kurtz, L. A. (2008) Understanding Motor Skills in children with Dyspraxia, ADHD, Autism, And other Learning Disabilities. published f, editor. Iondon: Philadelphia.

Meegan, S., Maraj, B., Weeks, D., Chua, R. (2006) Gross motor skill aequisition in adolescents with down syndrome. Down syndrome research and practice. 9(3); 75-80.

Mohammadi, M., Abdolvahab, M., HadianM, M. R., Olyaei, G. R., Jalili, M., Karimi, H. (2009) The Investigation of effects of simultaneous stimulation of Exteroception and Proprioception on dexterity of 6-7 years old educable children with Down's syndrome. journal of rehabilitation university of social welfare \& rehabilitation sciences. 9(2); 6-11.

Molajani, R. (2006) Effect of sensory stimulation and motor training on handicraft skills of educable retarded children 2006.

Parham, L., Mailloux, Z. (2005) Sensory integration. Occupational therapy for children. ed t, editor. London. 356-87.

Reif, H. M., Field, T., Largie, S., Mora, D., Bornstein, J., Waldman, R. (2006) Children with down syndrome improved in motor functioning and muscle tone following massage therapy. Early child development and care. 176, 395-410.

Reynolds, C. (2019) A study of the effectiveness of sensory integration therapy on neurophysiological development. The british institute for learning development. 2010.

Sadati, A., Sazmand, A., Mirzaie, H., Karimloo, M. (2009) The effect of gross motor activities on attention process (sustained attention, attention shift) of boy students with Down syndrome who are

Soortigi, H., Sazmand, A., Kabalaei, A., Jadidi, H. (2008) Effect of Sensory Integration Therapy on Gross and Fine Motor Skills of 5-7 Years Old Children with Down Syndrome journal of rehabilitation university of social welfare \& rehabilitation sciences. 9(2). persian.

Warng, J. A. (2004). Study on gross motor skills of preschool children. Jornal of research in childhood education. 19(1), 32-43.

Yanik, M., Bumin, G., Kayhan, H. (2003) Effectiveness of two different sensory integration programs for children with spastic diplogic cerebral palsy. Disability and rehabilitation. 123(9), 1132- 44.

Zimmer, R., Christoforidis, C., Xanthi, P., Aggeloussis, N. A. K. (2008) The effects of a psychomotor training program on motor proficiency of Greek preschoolers. European psychomotricity Jornal. 1(2), 3-9. 